\title{
Presenting features and long-term effects of growth hormone treatment of children with optic nerve hypoplasia/septo-optic dysplasia
}

\author{
Amy M Vedin ${ }^{*}$, Hanna Karlsson², Cassandra Fink ${ }^{3}$, Mark Borchert ${ }^{3,4}$ and Mitchell E Geffner ${ }^{1,4}$
}

\begin{abstract}
Background: Optic nerve hypoplasia (ONH) with/or without septo-optic dysplasia (SOD) is a known concomitant of congenital growth hormone deficiency (CGHD).

Methods: Demographic and longitudinal data from KIGS, the Pfizer International Growth Database, were compared between 395 subjects with ONH/SOD and CGHD and 158 controls with CGHD without midline pathology.

Results: ONH/SOD subjects had higher birth length/weight, and mid-parental height SDS. At GH start, height, weight, and BMI SDS were higher in the $\mathrm{ONH} / \mathrm{SOD}$ group. After 1 year of $\mathrm{GH}$, both groups showed similar changes in height SDS, while weight and BMI SDS remained higher in the ONH/SOD group. The initial height responses of the two groups were similar to those predicted using the KIGS-derived prediction model for children with idiopathic GHD. At near-adult height, ONH/SOD and controls had similar height, weight, and BMI SDS.

Conclusions: Compared to children with CGHD without midline defects, those with ONH/SOD presented with greater height, weight, and BMI SDS. These differences persisted at 1 year of GH therapy, but appeared to be overcome by long-term GH treatment.
\end{abstract}

\section{Background}

Optic nerve hypoplasia (ONH) is a congenital anomaly often associated with hypopituitarism and brain malformations. It is relatively rare, with an incidence of 1 in 10,000 live births, and it equally affects boys and girls [1]. The term septo-optic dysplasia (SOD), historically and even today, is widely used interchangeably with that of $\mathrm{ONH}$. However, it is now known that absence of the septum pellucidum per se does not confer increased risk for growth hormone (GH) deficiency alone or as a component of hypopituitarism in children with $\mathrm{ONH}[2,3]$.

In a study of 47 subjects [age (mean \pm SD) $15.2 \pm 10.6$ months] with $\mathrm{ONH}$ followed until $59.0 \pm 6.2$ months of age, Ahmad, et al reported a prevalence of endocrinopathies of $71.7 \%$ (including $64.1 \%$ with GH-IGF-I axis abnormalities); these were not associated with $\mathrm{ONH}$ laterality, absence of septum pellucidum, or pituitary abnormalities on neuro-imaging [2]. The only prior large,

\footnotetext{
* Correspondence: avedin@chla.usc.edu

${ }^{1}$ Center for Endocrinology, Diabetes, and Metabolism, Children's Hospital Los Angeles, 4650 Sunset Boulevard, Mailstop \#61, Los Angeles, CA 90027, USA Full list of author information is available at the end of the article
}

long-term study looking at growth outcomes in children described as having SOD treated with GH included 582 children enrolled in the National Cooperative Growth Study (NCGS) (Genentech, S. San Francisco CA). Among this cohort, 71 reached near-adult height (NAH) (mean $-1.57 \pm 1.27 \mathrm{SD}$ ), representing a mean gain of $1.17 \pm 1.49$ SD after 6-7 years of GH treatment [4].

More recently, it has been suggested that obesity is a frequent occurrence in children with $\mathrm{ONH}$ perhaps on a hypothalamic basis $[5,6]$. In his cohort of 47 subjects with $\mathrm{ONH}$, Ahmad found that $44 \%$ had a body mass index $(\mathrm{BMI})>85^{\text {th }}$ percentile at 5 years of age [2]. In the large NCGS study, no weight or BMI data were reported [4].

The purpose of the current analyses is to compare presenting features and short- and long-term auxological outcomes of GH treatment in children with $\mathrm{ONH}$ to those of patients with congenital growth hormone deficiency (CGHD) without non-pituitary midline defects or $\mathrm{ONH}$ using data from KIGS (the Pfizer International Growth Database). 


\section{Methods}

The KIGS database, established in 1987 and containing data from over 70,000 patients in 51 different countries, is an international registry developed with the main objective of documenting the long-term outcomes and safety of Somatonorm ${ }^{\circledR}$ and Genotropin ${ }^{\circledR} \mathrm{GH}$ products (Pfizer, Inc). The KIGS survey is performed in accordance with the recommendations adopted by the $18^{\text {th }}$ World Medical Assembly (held in Helsinki, Finland in 1964) and any subsequent revisions which exist to guide physicians carrying out biomedical research involving human individuals. Each subject and/or his/her legal representative receive adequate information, has the right to withdraw from the survey at any time, and consents his/her participation, although, during the first decade of its existence, this kind of registry or noninterventional trial that KIGS represents did not require informed consent from the subjects or legally acceptable representatives in many countries.

To capture subject data from KIGS for the current investigation, we included the diagnoses, $\mathrm{ONH}$ and/or SOD, since the latter is still widely used to describe patients with $\mathrm{ONH}$ whether or not the presence of the septum pellucidum is documented. Hereafter, for simplicity, we refer to the study condition as ONH/SOD. As of January 2009, there were 565 subjects identified as having CGHD secondary to ONH/SOD and 244 control subjects with CGHD unrelated to ONH/SOD and without extra-pituitary midline pathology. A list of the diagnostic codes included in the non-ONH/SOD CGHD group is included in Table 1. Subjects that were prepubertal and had at least one year of longitudinal data while receiving $\mathrm{GH}$ were included in the data analysis $(\mathrm{ONH} / \mathrm{SOD}$ group $\mathrm{n}=395$ and CGHD group $\mathrm{n}=158)$.

Background demographic characteristics, birth measurements, GH stimulation test results, and prevalence of associated hypothalamic-pituitary deficiencies affecting thyroid function, glucocorticoid production, and water metabolism (diabetes insipidus) were collected from KIGS. The prevalence of hypogonadism could only be obtained in older subjects who reached NAH. The

\begin{tabular}{|c|c|c|}
\hline $\begin{array}{l}\text { KIGS Diagnostic } \\
\text { Codes }\end{array}$ & $\mathrm{n}$ & Description \\
\hline 2.1.1.1 & 23 & $\begin{array}{l}\text { GH gene-defect (Type } 1 \mathrm{~A} \text { dominant or } \\
\text { recessive) }\end{array}$ \\
\hline 2.1.1.2 & 25 & GH gene-defect \\
\hline 2.1.1.3 & 4 & GHRH gene-defect \\
\hline 2.1.1.9 & 192 & Other genetic cause of GHD \\
\hline
\end{tabular}

$\mathrm{GH}$, growth hormone; GHRH, growth hormone releasing hormone; GHD, growth hormone deficiency subjects' additional hormonal deficiencies were also managed by their treating physicians. Auxological data at the time of initiation of GH therapy and after one year of treatment were also collected. Similar data of the subsets of the two groups who attained NAH were compared. NAH was defined by height velocity $(<2 \mathrm{~cm} /$ year), bone age ( $\geq 14$ years in females or $\geq 16$ years in males), and/or chronological age ( $>15$ years in females and $>17$ years in males).

Growth parameters are reported as standard deviation scores (SDS) which were calculated based on standards from Prader et al [7] and, for weight data, from Freeman et al [8]. Birth weight and length SDS were calculated using the reference of Niklasson et al [9]. Bone age readings were taken as reported by physicians and were based on the methods of Greulich and Pyle [10] or Tanner et al $[11,12]$. Data were not normally distributed and, therefore, are presented as median and $10^{\text {th }}$ and $90^{\text {th }}$ percentiles. Wilcoxon rank-sum test was used to detect differences between the two groups.

The heights of subjects in both groups were analyzed using the previously published KIGS prediction model for idiopathic GHD excluding GH maximum peak [13]. Differences between observed and predicted height velocities are expressed in terms of Studentized residuals. The residual is calculated as the observed height velocity minus the predicted height velocity for each observation, and the Studentized residual is the residual divided by its standard error.

\section{Results}

Background characteristics were compared between the two groups (Table 2). The birth length and weight SDS were significantly greater in the $\mathrm{ONH} / \mathrm{SOD}$ group compared to the non-ONH/SOD CGHD group [birth length SDS median $(0.27) ; 10^{\text {th }}$ and $90^{\text {th }}$ percentiles $(-1.3,2.0)$ vs. median $(-0.62) ; 10^{\text {th }}$ and $90^{\text {th }}$ percentiles $(-2.5,1.2) ; \mathrm{p}$ $<0.001)$ and birth weight SDS $(-0.31 ;-1.7,1.1)$ vs. $(-0.58 ;-2.0,1.0) ; \mathrm{p}=0.021)]$. Mid-parental height SDS was also significantly greater in the $\mathrm{ONH} / \mathrm{SOD}$ group $(-0.23 ;-1.8,1.3)$ compared to the non-ONH/SOD CGHD group [(-1.04; -3.0, 0.5); p < 0.001]. Peak GH levels on stimulation testing were similar between the two groups. The ONH/SOD group had significantly more subjects with other hypothalamic-pituitary hormone deficiencies compared to the non-ONH/SOD CGHD group (72.7\% vs. $51.9 \%$; $\mathrm{p}<0.001)$, with involvement of the thyroid and adrenal axes being the most common.

At the start of GH therapy, both groups had similar chronological ages and bone ages. However, the $\mathrm{ONH} /$ SOD group had significantly greater height SDS [(-3.00; $-4.8,-0.9)$ vs. $(-3.68 ;-6.7,-1.9) ; \mathrm{p}<0.001]$, weight SDS $[(-1.56 ;-4.2,0.5)$ vs. $(-2.56 ;-5.7,-0.6) ; \mathrm{p}<0.001]$, and 
Table 2 Characteristics at background, GH start, and $1^{\text {st }}$ year on GH

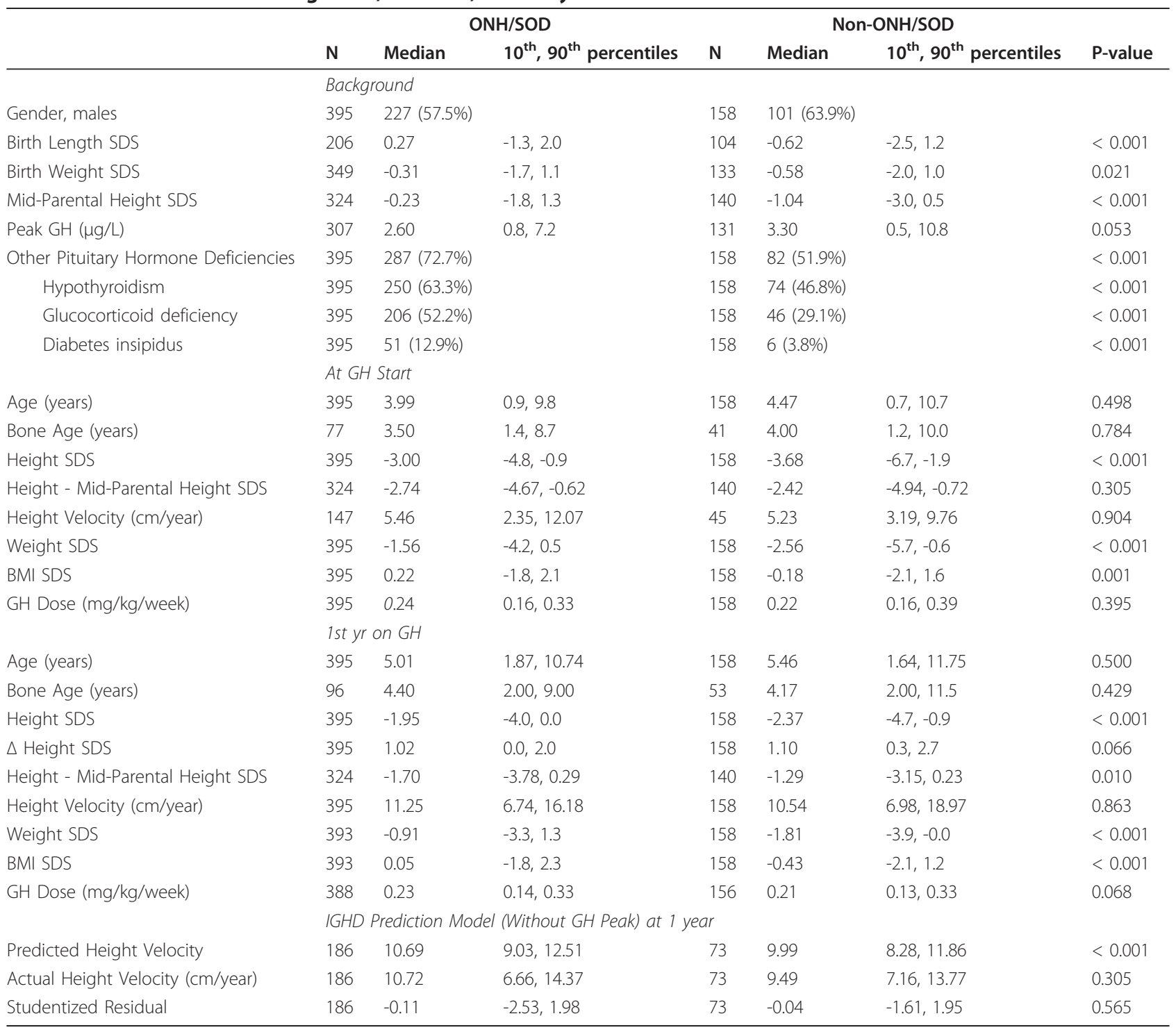

SDS, standard deviation score; GH, growth hormone

BMI SDS $[(0.22 ;-1.8,2.1)$ vs. $(-0.18 ;-2.1,1.6) ; \mathrm{p}=$ 0.001] (Table 2).

After one year on GH therapy, the two groups had similar changes in height SDS $(\mathrm{p}=0.066)$. The ONH/ SOD group continued to have a significantly higher height SDS, weight SDS, and BMI SDS after one year of GH therapy (all p < 0.001). However, height SDS corrected for family height genetics was significantly greater in the comparator group after the first year of $\mathrm{GH}$ treatment (Figure 1). Use of the prediction model for first-year growth response in children with idiopathic GHD showed that, although there was a slightly greater than predicted response in the ONH/SOD group versus the non-ONH/SOD CGHD group, there was no difference in actual height response between both groups, with Studentized residuals equivalent in both groups (Figure 2).

$\mathrm{NAH}$ data were available for 59 subjects in the $\mathrm{ONH} /$ SOD group and 23 subjects in the non-ONH/SOD CGHD group (Table 3). The two groups had similar $\mathrm{NAH}$ at approximately -1 SDS $(\mathrm{p}=0.430)$. The non$\mathrm{ONH} / \mathrm{SOD}$ CGHD attained a NAH that was closer to their mid-parental height $(\mathrm{p}<0.05)$. The two groups had similar weight SDS and BMI SDS at time of NAH (Figure 3). At NAH, the two groups had the same prevalence of hypogonadism.

\section{Discussion}

Although over half of the patients with ONH/SOD will develop an abnormality in their GH-IGF-I axis [2], 
(a)

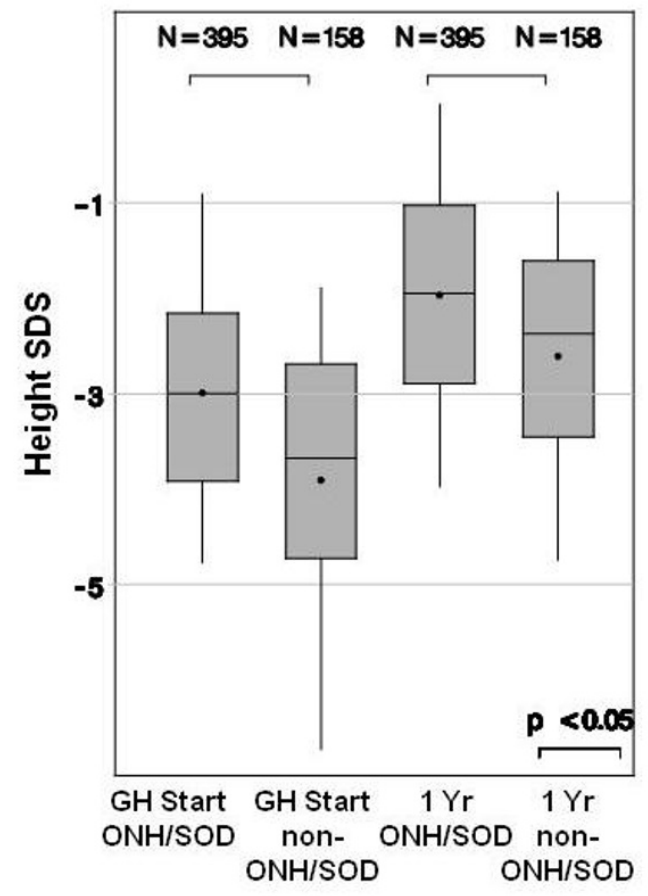

(c)

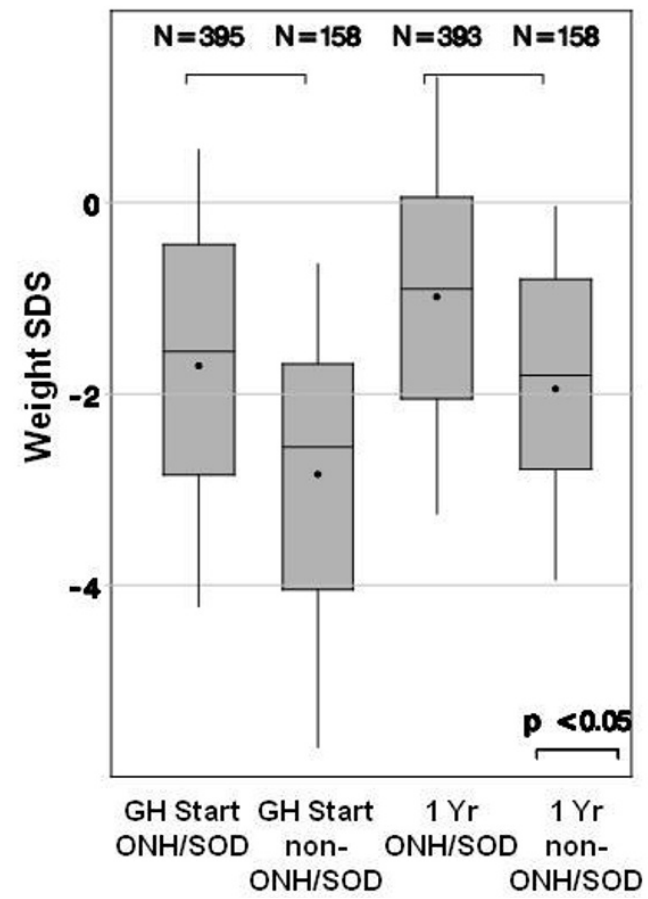

(b)

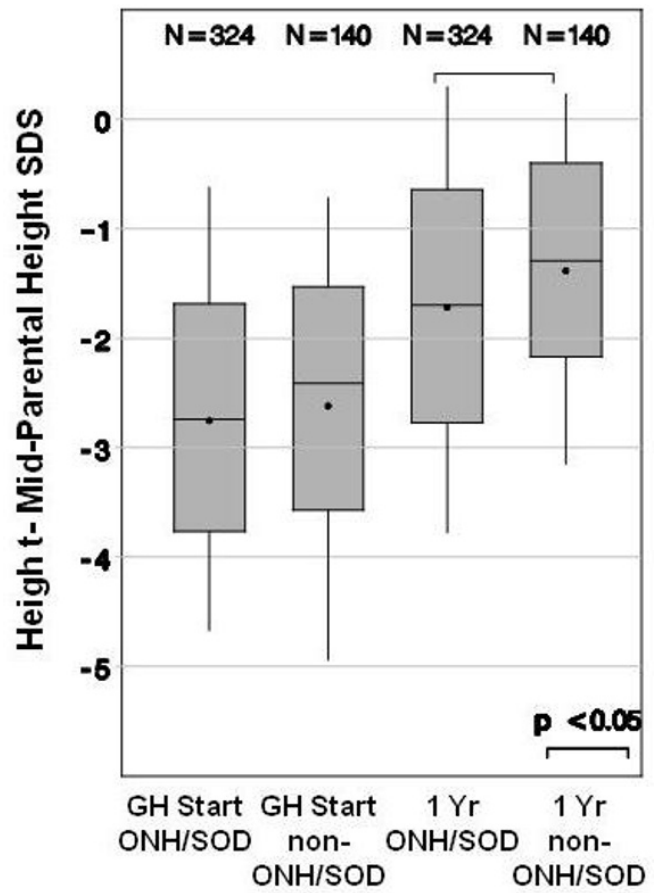

(d)

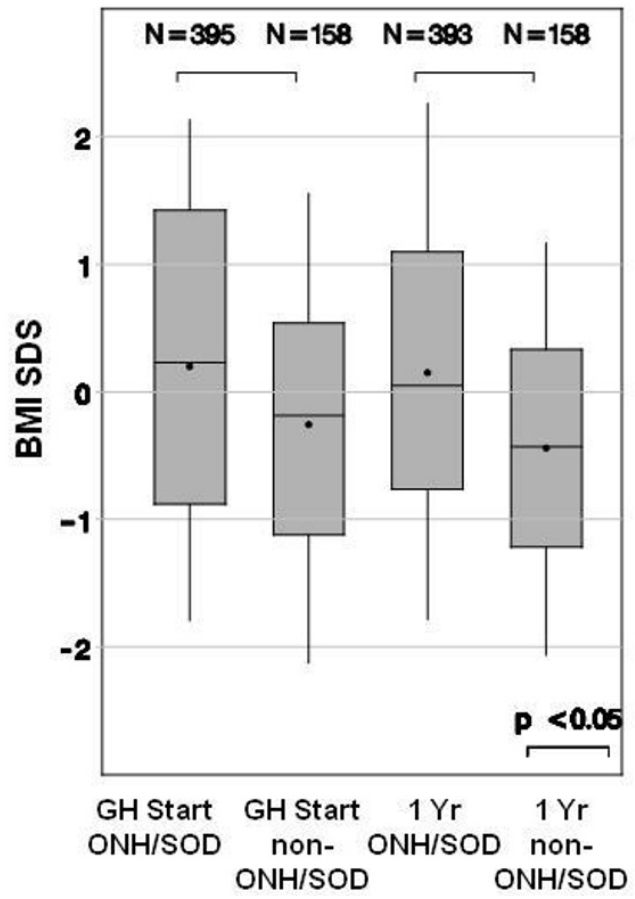

Figure 1 Comparison between groups. Comparison between groups with ONH/SOD vs. non-ONH/SOD CGHD of (a) height SDS, (b) height MPH SDS, (c) weight SDS, and (d) BMI SDS at start and after 1 year of GH therapy.

little is known about their clinical presentations and auxological responses to $\mathrm{GH}$, especially in comparison to those of similar patients with non-ONH/SOD CGHD.
In our study, the birth length and weight were significantly greater in the ONH/SOD group. It is unclear whether these differences can be fully explained by the increased mid-parental height seen in 

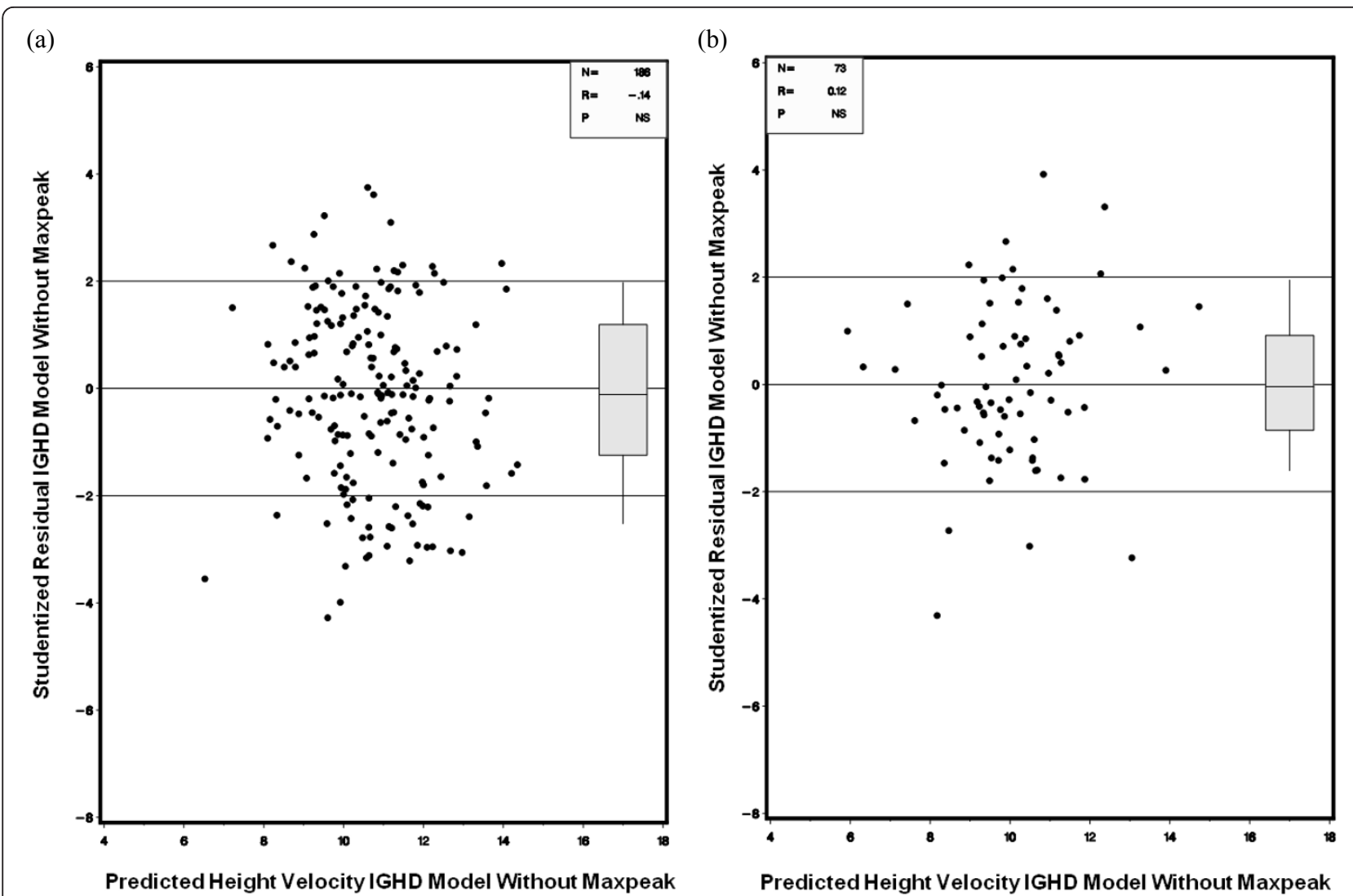

Figure 2 Differences between observed and predicted height velocities. Differences between observed and predicted height velocities after 1 year of GH therapy in (a) ONH/SOD group and (b) non-ONH/SOD CGHD group were expressed in terms of Studentized residuals.

Table 3 Characteristics at Near-Adult Height

\begin{tabular}{|c|c|c|c|c|c|c|c|}
\hline & \multirow[b]{2}{*}{$\mathbf{N}$} & \multicolumn{2}{|c|}{$\mathrm{ONH} / \mathrm{SOD}$} & \multicolumn{3}{|c|}{ Non-ONH/SOD } & \multirow[b]{2}{*}{ P-value } \\
\hline & & Median & $\begin{array}{l}10^{\text {th }}, 90^{\text {th }} \\
\text { percentiles }\end{array}$ & $\mathbf{N}$ & Median & $\begin{array}{l}10^{\text {th }}, 90^{\text {th }} \\
\text { percentiles }\end{array}$ & \\
\hline & \multicolumn{2}{|c|}{ At GH Start } & & & & & \\
\hline Gender, males & 59 & $26(44.1 \%)$ & & 23 & $10(43.5 \%)$ & & \\
\hline Age (years) & 59 & 5.64 & $2.14,11.76$ & 23 & 5.12 & $2.09,12.04$ & 0.546 \\
\hline Height SDS & 59 & -3.77 & $-5.51,-1.96$ & 23 & -4.97 & $-7.73,-2.98$ & $<0.001$ \\
\hline Height - Mid-Parental Height SDS & 48 & -3.41 & $-5.85,-1.78$ & 22 & -3.30 & $-5.81,-0.91$ & 0.658 \\
\hline Weight SDS & 59 & -2.23 & $-4.44,-0.72$ & 23 & -3.49 & $-5.92,-0.80$ & 0.013 \\
\hline BMI SDS & 59 & -0.13 & $-2.02,1.86$ & 23 & 0.09 & $-1.64,1.56$ & 0.955 \\
\hline \multirow[t]{2}{*}{ GH Dose (mg/kg/week) } & 59 & 0.21 & $0.14,0.31$ & 23 & 0.21 & $0.14,0.43$ & 0.996 \\
\hline & \multicolumn{2}{|c|}{ At $\mathrm{NAH}$} & & & & & \\
\hline Age (years) & 59 & 17.73 & $15.5,20.5$ & 23 & 17.30 & $15.3,19.4$ & 0.369 \\
\hline Height SDS & 59 & -0.87 & $-2.8,0.6$ & 23 & -1.37 & $-2.7,0.2$ & 0.430 \\
\hline$\triangle$ Height SDS (Latest minus Start) & 59 & 2.75 & $1.1,4.4$ & 23 & 3.37 & $1.6,6.1$ & 0.025 \\
\hline Height - Mid-Parental Height SDS & 48 & -0.63 & $-2.35,0.87$ & 22 & 0.37 & $-1.59,1.43$ & 0.004 \\
\hline Weight SDS & 59 & -0.53 & $-2.6,2.7$ & 23 & -0.22 & $-2.1,1.9$ & 0.988 \\
\hline BMI SDS & 59 & 0.32 & $-1.90,2.50$ & 23 & 0.59 & $-0.90,2.50$ & 0.581 \\
\hline Mean Total GH Dose (mg/kg/week) & 59 & 0.19 & $0.13,0.28$ & 23 & 0.19 & $0.14,0.25$ & 0.722 \\
\hline Years on GH Treatment & 59 & 11.15 & $6.69,16.37$ & 23 & 11.51 & $6.71,14.69$ & 0.996 \\
\hline Hypogonadism & 59 & $23(39.0 \%)$ & & 23 & $9(39.1 \%)$ & & \\
\hline
\end{tabular}

SDS, standard deviation score; GH, growth hormone 
(a)

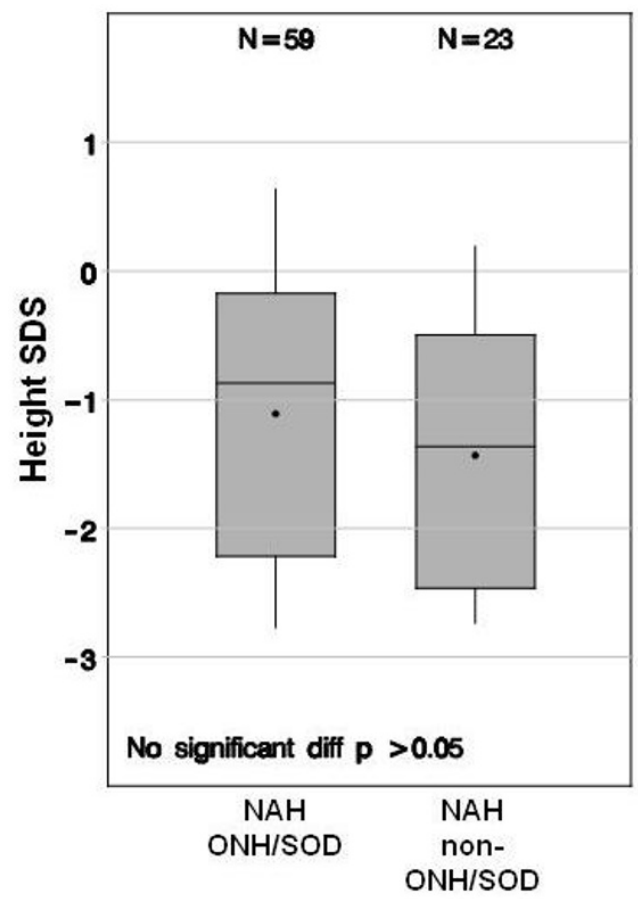

(c)

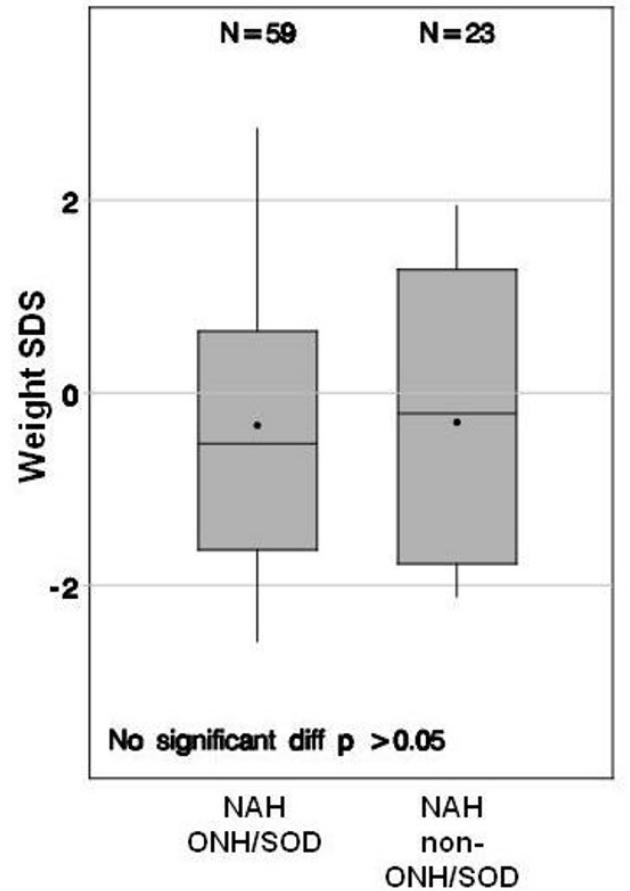

(b)

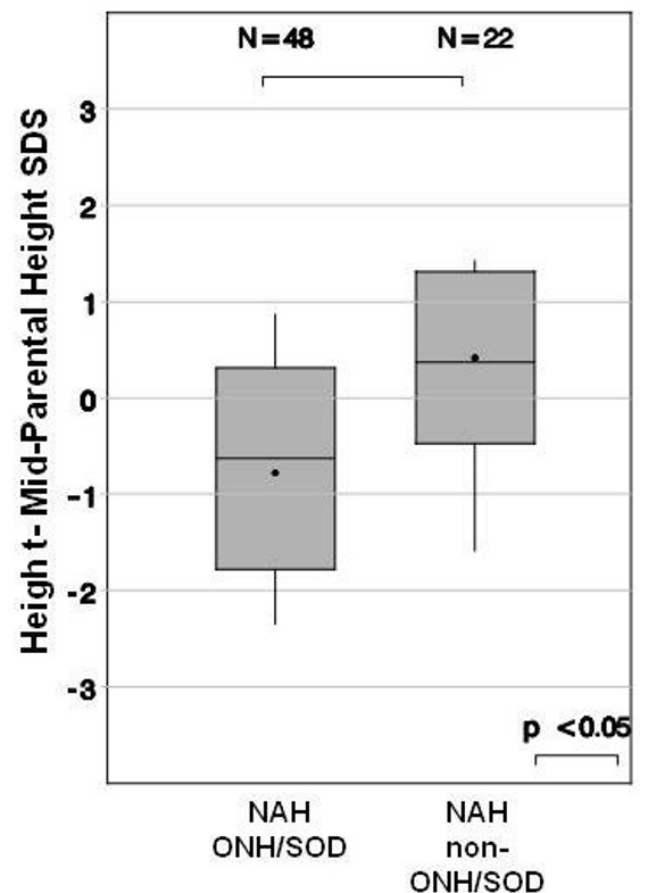

(d)

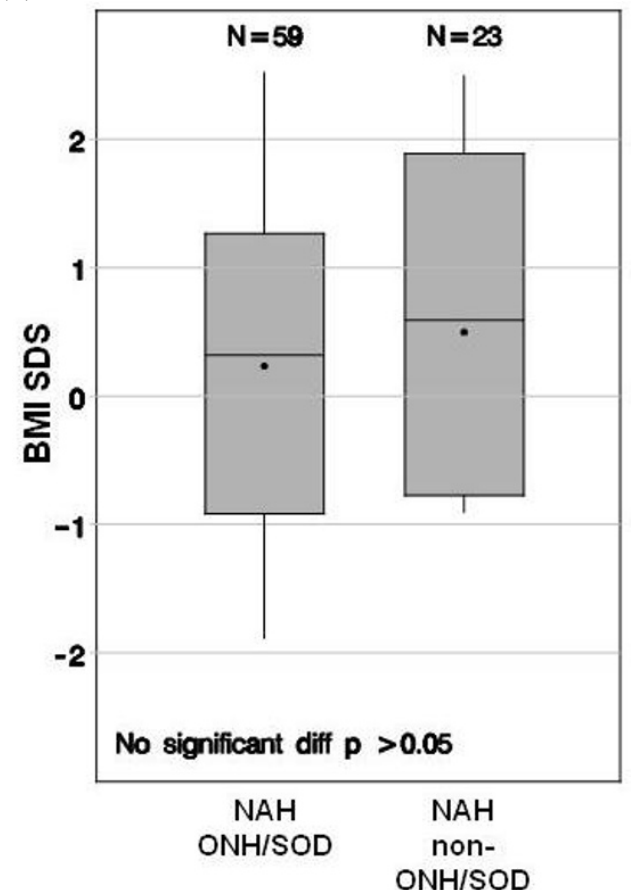

Figure 3 Comparison between groups with ONH/SOD vs. non-ONH/SOD CGHD. Comparison between groups with ONH/SOD vs. non-ONH/ SOD CGHD of (a) height SDS, (b) height - MPH SDS, (c) weight SDS, and (d) BMI SDS at near-adult height.

the ONH/SOD group or if there might be other disease-specific explanations. Some of this difference in mid-parental height may be due to the parents of those children with non-ONH/SOD CGHD also having the same gene defect causing short stature. At the time of diagnosis, the two groups had similar stimulated peak GH levels suggesting a comparable degree of GH deficiency. 
The higher prevalence of pituitary hormone deficiencies seen in the ONH/SOD group compared to the non$\mathrm{ONH} / \mathrm{SOD}$ CGHD group is not surprising given the known association of $\mathrm{ONH} / \mathrm{SOD}$ with hypopituitarism. However, our study found, at the time of GH initiation, for no obvious reason, a much higher prevalence of associated hormone deficiencies in the ONH/SOD group compared to the data reported in the NCGS study (hypothyroidism: $63.2 \%$ vs $27 \%$, glucocorticoid deficiency: $52.2 \%$ vs $24 \%$, and diabetes insipidus: $12.9 \%$ vs $5 \%$ ) [4]. In a smaller subset who reached NAH, 39\% of subjects in our cohort had hypogonadism while this data was not reported in the NCGS study.

At the time of $\mathrm{GH}$ initiation, the $\mathrm{ONH} / \mathrm{SOD}$ group was significantly larger than the non-ONH/SOD CGHD group in all measures (height, weight, and BMI). The taller heights at diagnosis in the ONH/SOD group might relate to the associated ophthalmological manifestations of the condition leading to nystagmus and earlier referral. This group's greater genetic height potential might also be contributory. As for the higher weight and BMI, this may be associated with the intrinsic hypothalamic dysfunction seen in some patients with $\mathrm{ONH} / \mathrm{SOD}$ causing hyperphagia.

The two groups responded similarly to one year of GH therapy with a comparable increase in height and similar to that predicted using the KIGS-derived prediction model for first-year growth in GH-treated children with idiopathic GHD. As a result, the ONH/SOD group continued to have significantly greater height, along with weight and BMI, than did the non-ONH/SOD CGHD group. Although we recognize the small size of the subsets from both groups that attained NAH and the inherent uncertainty of being able to draw firm conclusions as a result, the available data suggest that the two groups have similar height, weight, and BMI at NAH. With height outcomes in both groups within 1 $\mathrm{SD}$ of the mean (corrected for their respective mid-parental heights), this suggests that there is excellent adult height potential in children with congenital GH deficiency. Furthermore, these results suggest that longterm GH therapy can possibly prevent, minimize, and/or reverse the obesity that has been described in patients with $\mathrm{ONH} / \mathrm{SOD}$. Additional randomized prospective studies of GH therapy in patients with ONH/SOD are needed to investigate the effects of GH therapy specifically on obesity and body composition.

In summary, children with ONH/SOD have different presenting characteristics, but similar and normal final height responses to GH therapy compared to children with non-ONH/SOD CGHD. Because ONH/SOD is a major risk factor for CGHD and these patients may not be as short as those with non-ONH/SOD CGHD, it is important for clinicians to have a high index of suspicion and begin screening these patients for CGHD as early as possible. GH therapy may have additional benefits in this patient population as well with regard to body composition thus making early diagnosis and treatment even more important.

\section{Abbreviations}

ONH: Optic nerve hypoplasia; SOD: septo-optic dysplasia; GH: growth hormone; NCGS: National Cooperative Growth Study; NAH: near-adult height; CGHD: congenital growth hormone deficiency; SDS: standard deviation score

\section{Acknowledgements}

The authors express their thanks to the clinicians who provided the data on their patients. KIGS is supported by Pfizer, Inc. No authors were paid for their contributions to this manuscript.

\section{Author details}

${ }^{1}$ Center for Endocrinology, Diabetes, and Metabolism, Children's Hospital Los Angeles, 4650 Sunset Boulevard, Mailstop \#61, Los Angeles, CA 90027, USA. ${ }^{2}$ Pfizer Inc., Pfizer Endocrine Care, KIGS/KIMS/ACROSTUDY, SE-191 90 Sollentuna, Sweden. ${ }^{3}$ The Vision Center, Children's Hospital Los Angeles, 4650 Sunset Boulevard, Mailstop \#88, Los Angeles, CA 90027, USA. ${ }^{4}$ Saban Research Institute of Children's Hospital Los Angeles, 4650 Sunset Boulevard, Los Angeles, CA 90027, USA.

\section{Authors' contributions}

AV participated in the design of the study and drafted the manuscript. HK participated in the design of the study and performed the statistical analyses. CF and MB participated in the study's design and coordination. MG conceived of the study, and participated in its design and coordination. All authors read and approved the final manuscript.

\section{Competing interests}

HK is a full-time employee of Pfizer Endocrine Care, KIGS/KIMS/ACROSTUDY, Sollentuna, Sweden. MG receives funding from Pfizer for institutional participation in KIGS (Pfizer International Growth Database); for research subject participation in the multi-center clinical trial: "A Four-Year OpenLabel Multi-Center Randomized Two-Arm Study of Genotropin in Idiopathic Short Stature Patients: Comparing an Individualized, Target-Driven Treatment Regimen to Standard Dosing of Genotropin," and for serving as a member of national and international KIGS advisory boards.

Received: 26 July 2011 Accepted: 15 November 2011

Published: 15 November 2011

\section{References}

1. Patel L, McNally RJ, Harrison E, Lloyd IC, Clayton PE: Geographical distribution of optic nerve hypoplasia and septo-optic dysplasia in Northwest England. J Pediatr 2006, 148(1):85-88.

2. Ahmad T, Garcia-Filion P, Borchert M, Kaufman F, Burkett L, Geffner M: Endocrinological and auxological abnormalities in young children with optic nerve hypoplasia. J Pediatr 2006, 148(1):78-84.

3. Brodsky MC, Glasier CM: Optic nerve hypoplasia. Clinical significance of associated central nervous system abnormalities on magnetic resonance imaging. Arch Ophthalmol 1993, 111:66-74.

4. Parker KL, Hunold JJ, Blethen SL: Septo-optic dysplasia/optic nerve hypoplasia: data from the National Cooperative Growth Study (NCGS). J Pediatr Endocrinol Metab 2002, 15(suppl 2):697-700.

5. Borchert M, Garcia-Filion P: The syndrome of optic nerve hypoplasia. Curr Neurol Neurosci Rep 2008, 8(5):395-403.

6. Webb EA, Dattani MT: Septo-optic dysplasia. Eur J Hum Genet 2010 18(4):393-397.

7. Prader A, Largo RH, Molinari L, Issler C: Physical growth of Swiss children from birth to 20 years of age; first Zurich longitudinal study of growth and development. Helv Paediatr Acta 1989, 52(suppl):1-125. 
8. Freeman JV, Cole TJ, Chinn S, Jones PR, White EM, Preece MA: Cross sectional stature and weight references for the UK, 1990. Arch Dis Child 1995, 73:17-24.

9. Niklasson A, Ericson A, Fryer JG, Karlberg J, Lawrence C, Karlberg P: An update of the Swedish reference standards for weight, length and head circumference at birth for given gestational age (1977-1981). Acta Paediatr Scand 1991, 80:756-762.

10. Greulich WW, Pyle Sl: Radiographic Atlas of Skeletal Development of Hand and Wrist. Stanford, Stanford University Press; 21959.

11. Tanner JM, Landt KW, Cameron N, Carter BS, Patel J: Prediction of adult height and bone age in children. A new system of equations (TW mark II) based on sample including very tall and very short children. Arch Dis Child 1983, 58:767-776.

12. Tanner JM, Healy MJR, Goldstein H, Cameron N: Assessment of Skeletal Maturity and Prediction of Adult Height (TW3) Method. Singapore, WB Saunders; 32001

13. Ranke MB, Lindberg A, Chatelain P, Wilton P, Cutfield W, AlbertssonWikland K, Price DA: Derivation and validation of a mathematical model for predicting the response to exogenous recombinant human growth hormone $(\mathrm{GH})$ in prepubertal children with idiopathic GH deficiency. J Clin Endocrinol Metab 1999, 84:1174-1183.

doi:10.1186/1687-9856-2011-17

Cite this article as: Vedin et al:: Presenting features and long-term effects of growth hormone treatment of children with optic nerve hypoplasia/septo-optic dysplasia. International Journal of Pediatric Endocrinology 2011 2011:17.

\section{Submit your next manuscript to BioMed Central and take full advantage of:}

- Convenient online submission

- Thorough peer review

- No space constraints or color figure charges

- Immediate publication on acceptance

- Inclusion in PubMed, CAS, Scopus and Google Scholar

- Research which is freely available for redistribution

Submit your manuscript at www.biomedcentral.com/submit 